\title{
ON VALUE MAXIMIZATION AND ALTERNATIVE OBJECTIVES OF THE FIRM
}

\section{S. J. Grossman and J. E. Stiglitz*}

THE RECENT LITERATURE on firm behavior has been characterized by two contrasting strands of analysis: on the one hand, there is the literature attempting to extend the conventional maxims of profit maximization of competitive firms from the familiar static models to dynamic contexts and into situations of uncertainty. These analyses argue that firms should maximize their stock market value and explore the implications of this for firm behavior. On the other hand, there is the vast and growing "managerial" literature, in which other objectives, such as "satisficing," "sales maximizing," and "maximization of the manager's utility functions" are postulated. The second group of analyses criticize the first as being unrealistic, while the first argues that it provides the best "first approximation" to firm behavior: if firms did not maximize their stock market value, or deviated far from value maximization, someone would attempt to take them over, change the course of action of the firm, and make a pure capital gain. This paper presents a unified framework for analyzing firm behavior which can be used to reconcile these divergent views.

We begin our analysis by taking seriously several aspects of modern corporations which are usually ignored: there exist shareholders' meetings, the right to vote at these shareholders' meetings often has market value (market prices for voting and non-voting shares often differ); disagreements occasionally arise at these meetings; takeover bids are not uncommon; and takeovers are often disputed. The modern corporation is an economic institution in which there is always a potential political (i.e. voting) aspect. Thus, we model the firm as if the action it takes were determined by a majority vote of its shareholders. In deciding what action to vote for, shareholders must have some expectations of the consequences of alternative actions; in particular, we consider a small firm, so that it is not unreasonable for the individual to assume that the actions and values of all other firms will be unaffected. Thus we take the conventional Nash-non-cooperative view of market equilibrium. On the other hand, the action of the firm may have an effect on the market value of the firm in question, and it may lead individuals to decide to reallocate their portfolios. ${ }^{1}$ We postpone until later a more detailed discussion of what a market equilibrium would look like in this context; but the simplest case to analyze is that where all individuals agree on what action the firm ought to take. In some sense, when that is the case, the shareholders' meeting is redundant.

Section 1 of this paper gives an introduction to our result that in many cases

- Stanford University. This work was supported in part by National Science Foundation Grants SOC74-22382, SOC74-11446-A01 and SOC76-18771. The authors are also indebted to the Dean Witter Foundation and IBM. We are very grateful to Oliver Hart for helpful comments.

1. For an earlier discussion of the voting-shareholders' model of the corporation, see Stiglitz [1970]. 
where a stock is traded, it seems clear that there will not be stockholder unanimity. Section 2 sets up a formal model. Sections 3 and 4 critically survey the results on unanimity in the context of a multiperiod model. Section 5 shows how unanimity theory can be used to prove and analyze the Modigliani-Miller theorem. Sections 6 and 7 discuss the value of value maximization, and some paradoxes involved in take-over bids.

\section{INTRODUCTION TO SHAREHOLDER UNANIMITY ,}

In the conventional static models the desirability of profit maximization is obvious; there are prices for all goods and factors. The firm's "value" is simply the value of output minus the value of inputs. All prices are known and the technology is known, so there is unanimity about what course of action leads to value maximization. Value maximization is desired by every individual because an increase in the market value of the firm simply moves the individual's budget constraint outward (in parallel, since prices are assumed to remain unchanged).

This result extends in a straightforward-and uninteresting-way to dynamic situations with uncertainty when there is a complete set of future and contingent claim (Arrow-Debreu) securities markets. Much of the recent literature on corporate firm behavior can be thought of as an attempt to extend these results on unanimity to situations where there is not a complete set of markets. It has been shown that unanimity obtains if there is no trade and if any production plan of the firm can be written as a linear combination of production plans of other firms; i.e. there is what has come to be called spanning.

The major argument of the paper is: (i) in any interesting market there will be trade, and then spanning does not imply unanimity; in particular, we examine two situations where trade is likely to be continuously generated; in one, trade is generated by the arrival of new information; it is obvious that differential information may give rise to trade, but even if the new information is obtained by everyone, if individual tastes (attitudes towards risk) differ, the equilibrium portfolios will change in response to the new information. In the other, trade is generated by life cycle considerations: every period, there are individuals who retire and who sell their shares to new individuals who hold the shares as savings for retirement; (ii) if the financial decisions of the firms are also taken into account, spanning requires essentially a full set of markets and thus does not constitute any weakening of the classical result, and (iii) if in addition to spanning firms are assumed to behave as perfect competitors in the composite commodities which form a basis for the spanned space, then there is unanimity. We call this assumption "competitivity." However, the assumption of both spanning and competitivity lead to the very strong result that firms desire to maximize the net market value of their shares. Though this may sound like a satisfactory theory it is empirically false and leaves unexplained the numerous phenomena referred to in the introduction. In the concluding remarks we refer to empirical evidence for a particular class of firms where there is unambigous evidence against the hypothesis of value maximization. 


\section{A Simple Model: The Multiperiod Model without Debt}

The economy extends for three periods: 0,1 and 2. The state of the world, $\omega$ is composed of a signal $t$, which is known in period 1 and a final state $s$ which is known in period $2 ; \omega=(t, s)$. There is a single commodity which is available in each period and which is used for consumption and investment in period 0 , and for consumption only in both periods 1 and 2 .

In period 0 there are markets for the single current commodity and also for shares in firms. It is assumed that no contingent commodity contracts can be made. In period 1 there are markets for the single current commodity and also for shares in the firms. Consumers also get the signal $t$ which changes their beliefs about $s$ before trading in period 1 . In period 2 consumers are allocated output according to the shares held in firms at the end of period 1.

Let there be $I$ consumers, $J$ firms, $T$ signals and $S$ final states, indexed by $i=1, \ldots, I, j=1, \ldots, J, t=1, \ldots, T, s=1, \ldots, S$, respectively. Sometimes $I, J, T$ and $S$ will be referred to as the set of consumers, firms, signals and final states.

\section{Consumers}

We will represent consumer $i$ 's consumption plan by a vector $x_{i}=\left(x_{i}^{0}, x_{i}^{1}, x_{i}^{2}\right)$ $\in R_{+}^{1+T+T S}$, where $x_{i}^{0} \in R_{+}$is consumption in period 0 and $x_{i t}^{1} \in R_{+}$is consumption when there is signal $t$ in period 1 , and $x_{i}^{2}(\omega)=x_{i}^{2}(t, s) \in R_{+}$is consumption in period 2 when $(t, s)$ was realized. Consumer $i$ is assumed to have a utility function $U_{i}$ defined on $R_{+}^{1+T+T S}$. We will assume that $U_{i}$ is strictly quasi concave and continuously differentiable on the interior of its domain, and $\partial U_{i} / \partial x^{l} \rightarrow \infty$ as $x^{l} \rightarrow 0$ for $l=0,1$.

\section{Firms}

Firm $j$ 's production possibilities are represented by a production set $Y_{j} \subset R_{+}^{S+1}$. If $y_{j} \in Y_{j}$ we write $y_{j}=\left(\mathrm{y}_{j}^{0}, y_{j}^{2}\right)$ where $y_{j}^{0} \in R_{+}$is the input in period 0 and $y_{j}^{2}(s) \in R_{+}$ is the output in period 2 , state $s$. Note that inputs appear as non-negative numbers. We will assume that $Y_{j}$ is convex, closed and contains the origin. Further if $y_{j} \in Y_{j}$ and $y_{j}^{0}=0$, then $y_{j}^{2}=0$.

It is assumed that consumer $i$ has initial endowments $\bar{x}_{i}^{0} \in R_{+}, \bar{x}_{i}^{1} \in R_{+}^{T}$ of the commodity in periods 0 and 1 respectively. He also has initial shareholdings $\bar{\theta}_{i j} \geqslant 0$ in firm $j$ where $\sum_{i} \bar{\theta}_{i j}=1$ for each $j$. For notational simplicity we ignore endowments in period 2. Let $\bar{X}^{0}=\sum_{i} \bar{x}_{i}^{0}$, and assume $\bar{X}^{0}>0$.

\section{Equilibrium for Fixed Production Plans}

Let $y_{j}$ be given for each $j=1, \ldots, J$. The $i$ th consumer maximizes $U_{i}\left(x_{i}^{0}, x_{i}^{1}, x_{i}^{2}\right)$ with respect to $\left(\theta_{i j}, \theta_{i j}(t), x_{i}\right), j=1, \ldots, J, t=1, \ldots, T$ subject to: the individual's second period budget constraint,

$$
x_{i}^{2}(s, t)=\sum_{j} \theta_{i j}(t) y_{j}^{2}(s)
$$

the individual's first period budget constraint,

$$
x_{i}^{l}(t)+\sum_{j} p_{j}(t) \theta_{i j}(t) \leqslant \sum_{j} p_{j}(t) \theta_{i j}+\bar{x}_{i}^{1}(t)
$$


(consumption plus the value of shareholdings at the end of the period (after trade) must be less than or equal to the value of shareholdings at the beginning of the period (before trade) plus the endowment); and the individual's 0th period budget constraint;

$$
x_{i}^{0}+\sum_{j} p_{j} \theta_{i j} \leqslant \sum_{j} \bar{\theta}_{i j}\left(p_{j}-y_{j}^{0}\right)+\bar{x}_{i}^{0}
$$

where $x_{i}^{2}(s, t)$ is the $(s, t)$ th component of $x_{i}^{2} ; \theta_{i j}(t)$ is the desired holdings of firm $j$, in period 1 if $t$ is the information signal; $x_{i}^{1}(t)$ is the $t$ th component of $x_{i}^{1} \cdot p_{j}(t)$ is the price of firm $j$ in period 1 , signal $t . p_{j}$ is the price of firm $j$ in period $0 . \theta_{i j}$ are the desired holdings of firm $j$ in period 0 . In (3) we have assumed that inputs, $y_{j}^{0}$, are financed by the issuance of equity alone.

With no constraint against short sales (i.e. we don't require $\theta_{i j}$ or $\theta_{i j}(t)$ to be non-negative) necessary and sufficient conditions for solution to the maximum problem are that there exist multipliers $\left(\lambda_{i}^{0}, \lambda_{i}^{l}\right)$ such that $\lambda_{i}^{0} \in R_{+}$and $\lambda_{i}^{l} \in R_{+}^{T}$ such that

$$
\begin{gathered}
\nabla_{0} U_{i}=\lambda_{i}^{0}, \quad \nabla_{1} U_{i}=\lambda_{i}^{1} \\
\lambda_{i}^{0} p_{j}=\sum_{t} \lambda_{i t} p_{j}(t), \quad j=1, \ldots, J \\
\nabla_{2 t} U_{i} \cdot y_{j}^{2}=\lambda_{i t} p_{j}(t), \quad j=1, \ldots, J, \quad t=1, \ldots, T,
\end{gathered}
$$

where $\nabla_{0} U_{i} \equiv \partial U_{i}\left(x_{i}\right) / \partial x_{i}^{0}$, and $\nabla_{2 t} U_{i} \equiv\left[\partial U_{i}\left(x_{i}\right) / \partial x_{i}^{2}(t, s)\right]_{s=1}^{s}$, and $\lambda_{i t}$ is the $t$ th component of $\lambda_{i}$.

Equation (4) provides the interpretation of the Lagrange multipliers $\lambda_{i}^{0}$ and $\lambda_{i}^{1}$ as the marginal utility of consumption between the 0 th and 1 st periods. The interpretation of (5) is perhaps clearer if we rewrite it as: $p_{j}=\sum_{t}\left(\nabla_{2 t} U_{i} / \nabla U_{t}\right) \cdot y_{j}^{2}$; the price at date 0 equals the weighted average of the returns at date 2 , with weights equal to the marginal rate of substitution between goods at date 0 and date 1 - signal $t$.

Equation (6) has the interpretation that the price (value) of a share in state $t$ is equal to the marginal utility generated by buying an extra share of the firm, normalized by the marginal utility of income in state $t$.

A competitive exchange equilibrium for the economy, relative to the production plans $\left(y_{j}\right)$ is then a collection $\left(x_{i}\right),\left(\theta_{i j}\right),\left(\theta_{i j}(t)\right),\left(p_{j}\right)$ and $\left(p_{j}(t)\right)$ such that (4)-(6) hold for each consumer and the commodity market at time 0 and 1 and the share markets at time 0 and 1 all clear:

$$
\begin{gathered}
\sum_{i} x_{i}^{0}+\sum_{j} y_{j}^{0}=\bar{X}^{0}, \sum_{i} \theta_{i j}=1, \sum_{i} \theta_{i j}(t)=1, \\
\text { and } \quad \sum_{i} x_{i}^{\prime}(t)=\sum_{i} \bar{x}_{i}^{1}(t), \forall t \in T .
\end{gathered}
$$

In the above economy, firms fix their inputs in period 0 and output is realized in period 2. In period 1 consumers get new information about the distribution of firm 
output in period 2, so they have the opportunity to recontract away from their period zero holdings of firm shares. In period 2, state $s$, each consumer gets the output that corresponds to his share of the firms he owns.

In the above definition of equilibrium we took as exogenously given the production plans of all firms. We now exposit some methods of determining production plans as well as exchange equilibrium. It is useful to parameterize the firm's choice of production plan; we let $\tilde{y}_{j}\left(\rho_{j}\right)=y_{j}$, and assume a small change in $\rho_{j}$ corresponds to a small change in $y_{j}{ }^{2}$

The crucial part of an analysis involves examining how the stockholders of firm $j$ feel about a small change from $\rho_{j}$ to $\rho_{j}+d \rho_{j}$. To see this we totally differentiate a consumer's utility function with respect to $\rho_{j}$. That is, we define

$$
U_{i}^{*}\left(\rho_{j}\right) \equiv \max _{\left(x_{i}, \theta_{i j}, \theta_{i j}(t)\right)} U_{i}\left(x_{i}\right) \text { subject to (1)-(3). }
$$

By direct calculation

$$
\begin{aligned}
\frac{d U_{i}^{*}}{d \rho_{j}}= & \left\{\lambda_{i}^{0}\left(\bar{\theta}_{i j}-\theta_{i j}\right) \frac{d p_{j}}{d \rho_{j}}+\sum_{t=1}^{T} \lambda_{i t}\left(\theta_{i j}-\theta_{i j}(t)\right) \frac{d p_{j}(t)}{d \rho_{j}}\right\} \\
& +\sum_{t} \theta_{i j}(t) \nabla_{2 t} U_{i} \frac{d y_{j}^{2}}{d \rho_{j}}-\lambda_{i}^{0} \bar{\theta}_{i j} \frac{d y_{j}^{0}}{d \rho_{j}}
\end{aligned}
$$

In deriving equation (8) we have used equations (4)-(6) and the assumption:

$$
\frac{d p_{k}(t)}{d \rho_{j}}=\frac{d y_{k}}{d \rho_{j}}=\frac{d p_{k}}{d \rho_{j}}=0 \quad \text { for } \quad k \neq j, \forall t \in T .
$$

That is, when the $j$ th firm changes its production decision no change is assumed to occur in all other firms' production decisions and prices. (Here we are already making assumptions about the degree of competition among firms or, implicitly imposing a Nash equilibrium notion on firm behavior.) If (8) has the same sign for all individuals, there is unanimity with respect to different individual evaluations of alternative production plans. The question is when will (8) have the same sign for all individuals. It is our objective to show that the assumption of "spanning," which is made to get unanimity in a two period context, is not sufficient in a three period context. We will show that in addition to spanning the stronger assumption of competitivity (to be defined below) is a sufficient condition for unanimity in a two period context (i.e. one trading period).

\section{Unanimity with Only One Trading Period}

Suppose we close the market for shares in period 1, or that with the market open all traders decide not to trade. In this case the firm makes its decision in period 0 and in period 2 consumers get their period 0 shares of the firm's period 2 output. That

2. We will assume that mapping $\tilde{y}_{j}$ can be found such that the exchange equilibrium prices are differentiable functions of $\rho_{j}$. 
is $\theta_{i k}=\theta_{i k}(t)$ for all $t$, so equation (8) can be written as

$$
\frac{d U_{i}^{*}}{d \rho_{j}}=\lambda_{i}^{0}\left[\left(\bar{\theta}_{i j}-\theta_{i j}\right) \frac{d p_{j}}{d \rho_{j}}-\bar{\theta}_{i j} \frac{d y_{j}^{0}}{d \rho_{j}}\right]+\theta_{i j} \sum_{t} \nabla_{2 t} U_{i} \frac{d y_{j}^{2}}{d \rho_{j}} .
$$

The first term on the right hand side of (10) represents a wealth (i.e. a capital gains) effect, while the second term represents a consumption effect (i.e. the change in utility due to a change in the composition of date 2 consumption).

The first term makes clear that capital gains are only important to the extent that the individual is a seller of the security, i.e. his initial endowment $\bar{\theta}_{i j}$ exceeds his planned holdings of shares at the end of the period. (The term $\bar{\theta}_{i j}\left(d y_{j}^{0} / d \rho_{j}\right)$ comes from the particular specification of how in effect an additional investment is financed; i.e. from compulsory payments from the original shareholders.)

The distinction between the consumption and capital gains effects is very clear in a different context: suppose there were a single producer of automobiles, and because of technological considerations, all automobiles had to be either blue or pink. Suppose, too, that more people preferred blue cars, so that the value of the firm would be maximized by producing blue cars. But if a shareholder also consumes cars, and knows that the production decision of the firm is going to affect his "consumption set"-i.e. if the firm produces blue cars, he cannot purchase a pink car, then a shareholder with a strong preference for pink cars, may vote for producing pink cars, even when there is considerable loss in market value as a result. In the context of the stock market, the point is that whenever there is not a full set of contingent claims markets, there is always the possibility that the slope of the budget constraint is altered, not in the dramatic way of the previous example (where the implicit relative price of the two kinds of cars, pink and blue, is altered from infinity to zero) but still altered in an important way.

Thus, the search for conditions for unanimity breaks down into looking for conditions under which (a) there is unanimity about the sign of the consumption effect, (b) there is unanimity about the sign of the wealth effect, and (c) there is unanimity about the relative importance of the two.

Assume that there was a complete set of securities; then $\sum_{t} \nabla_{2 t} U_{i}=\lambda_{i}^{0} q(s)$ where $q(s)$ is the market price for income in state $s$. Using (10) and (4)-(6) we obtain

$$
\frac{d U_{i}^{*}}{d \rho_{j}}=\lambda_{i}^{0}\left[\left(\bar{\theta}_{i j}-\theta_{i j}\right) \frac{d p_{j}}{d \rho_{j}}-\bar{\theta}_{i j} \frac{d y_{j}^{0}}{d \rho_{j}}+\theta_{i j} \sum_{s} q(s) \frac{d y_{j}^{2}(s)}{d \rho_{j}}\right] .
$$

Note that now the consumption effect is the same for all individuals. Moreover, in that situation

$$
\frac{d p_{j}}{d \rho_{j}}=\sum_{s} q(s) \frac{d y_{j}^{2}(s)}{d \rho_{j}}
$$

The change in the market value is simply the value-at market prices-of the change in inputs and outputs. The $\theta_{i j}$ term then cancels, and we obtain $d U_{i}^{*} / d \rho_{j}$ $=\lambda_{i}^{0} \bar{\theta}_{i j}\left[\left(d p_{j} / d \rho_{j}\right)-\left(d y_{j}^{0} / d \rho_{j}\right)\right]$, the change in the net market value. This is the 
standard result. Note, however, that there were two distinct stages in the analysis. The first involved obtaining agreement on the consumption effect, the second involved relating the magnitude of the consumption effect to the capital gain effect. Thus, if there were taxes, leading to a discrepancy between consumer and producer prices, i.e. so that equation (12) did not obtain, then unanimity about the consumption effect would not imply overall unanimity.

It is obviously not necessary to have a complete set of securities to obtain unanimity on the consumption effect. Stiglitz [1970] noted two conditions under which unanimity on the consumption effect obtained: (a) if there is multiplicative uncertainty, so that (with suitable parameterization) $d y_{j}^{2} / d \rho_{j}=y_{j}^{2}$, we obtain directly from (4) and (6) the result that $\theta_{i j} \sum_{t} \nabla_{2 t} U_{i}\left(d y_{j}^{2} / d \rho_{j}\right)=\theta_{i j} \sum \nabla_{2 t} U_{i} \cdot y_{j}^{2}=\lambda_{i}^{0} \theta_{i j} p_{j}$ so the sign of the consumption effect is independent of $i$, for all shareholders of firm $j$, and (b) in the mean variance model (either a quadratic utility function or jointly normally distributed random variables), he also showed that the sign of the consumption effect is independent of $i$.

Ekern-Wilson [1974] and Leland [1974] have generalized the technological conditions under which stockholders are unanimous with respect to the sign of the consumption effect. Ekern-Wilson assume that any feasible change in a firm's output plan can be written as a linear combination of all firms' current output plans; with $\left\{y_{j}^{2}\right\}_{j=1}^{J}$ given, they assume that there exist real numbers $\hat{\alpha}_{j k}$ such that

$$
\frac{d y_{j}^{2}}{d \rho_{j}}=\sum_{k=1}^{J} \hat{\alpha}_{j k} y_{k}^{2}
$$

If (13) holds for $\left\{y_{j}\right\}_{j=1}^{J}$ we say there is spanning at $\left\{y_{j}\right\}_{j=1}^{J}$. Substituting to evaluate the consumption effect in (10), using (5) and (6) yields

$$
\theta_{i j} \sum_{t} \nabla_{2 t} U_{i} \frac{d y_{j}^{2}}{d \rho_{j}}=\theta_{i j} \sum_{t} \nabla_{2 t} U_{i} \sum_{k} \hat{\alpha}_{j k} y_{k}^{2}=\lambda_{i}^{0} \theta_{i j} \sum_{k} \hat{\alpha}_{j k} p_{k},
$$

the sign of which is independent of $i$ for all shareholders of firm $j$. Informally, if any output of the firm is a linear combination of the outputs of other firms then all traders must agree on the consumption effect of an output change, because consumption opportunities are unchanged.

Consumption unanimity, as we have emphasized, does not imply overall unanimity for there must be unanimity about the relative importance of the consumption effect and the capital gains effect. It turns out that to obtain the latter, only three general sets of conditions have been derived: (a) there is no capital gains effect, (b) there is no consumption effect, and (c) in addition to spanning we make the assumption (to be given formally below) of competitivity.

To see conditions under which (a) or (b) obtain Stiglitz [1970] suggested that it is useful to isolate two phases in a corporation's life cycle; in the early phase, a small group of investors own the firm and want to raise capital to expand, and each member wants to diversify his personal wealth into other securities. In this early phase, the initial stockholders have very large $\vec{\theta}_{i j}$ (initial holdings) relative to $\theta_{i j}$ (desired holdings). Thus, assuming that $\theta_{i j} \approx 0$ we can write (10) as $d U_{i}^{*} / d \rho_{j}$ 
$\approx \lambda_{i}^{0} \bar{\theta}_{i j}\left[\left(d p_{j} / d \rho_{j}\right)-\left(d y_{j}^{0} / d \rho_{j}\right)\right]$, i.e. the consumption effect is negligible; clearly in this case, all stockholders desire the firm to maximize net market value.

In the mature steady state stage of a firm's existence, stockholders simply hold their portfolio shares every period, e.g. in a world with no new information or other shocks hitting the market, a steady state ${ }^{3}$ means that $\theta_{i j}=\bar{\theta}_{i j}$, so the capital gains effect drops out, and we obtain only the consumption effect (where, obviously, if there is additional investment in the 0th period, we must take the cost of that into account). Ekern-Wilson [1974], Leland [1973], and Radner [1974] have used the assumption that $\theta_{i j}=\bar{\theta}_{i j}$ along with spanning to prove unanimity, and referred to this situation as ex post unanimity, to distinguish it from the case when the contraint is not imposed, which is called ex ante unanimity.

To see more precisely the nature of what is going on, it may be useful to consider a special case. Assume a mean variance model and a risk free asset with period 2 return defined as $R$; consider a firm whose returns are independently distributed from all other firms, and consider a change in its production plans which increases the output in all states of nature proportionately: $d \mu_{j} / d \rho_{j}=\mu_{j}, d \sigma_{j} / d \rho_{j}=\sigma_{j}$ where $\mu_{j}$ and $\sigma_{j}$ are the mean and standard deviations of the $j$ th firm's returns.

Assume that all traders have constant absolute risk aversion. Then the basic market valuation equation implies that there is a positive constant $k$ such that $p_{j}=\left(\mu_{j}-k \sigma_{j}^{2}\right) / R$. From the first order conditions for optimality there is a positive multiplier $\lambda_{i}^{*}$ such that

$$
\frac{d U_{i}^{*}}{d \rho_{j}}=\lambda_{i}^{*}\left[R\left(\bar{\theta}_{i j}-\theta_{i j}\right) \frac{d p_{j}}{d \rho_{j}}+\theta_{i j} R p_{j}\right]-\lambda_{i}^{*} R \bar{\theta}_{i j} \frac{d y_{j}^{0}}{d \rho_{j}} .
$$

The second term in brackets is the consumption effect, about which, all shareholders are unanimous. However, we now show that shareholders need not be unanimous regarding the production plan because of the capital gains term. Since $k$ is a constant relating to the risk aversions of the shareholders,

$$
\frac{d p_{j}}{d \rho_{j}}=p_{j}-\frac{k \sigma_{j}^{2}}{R}
$$

Using (15) and (16) together yields $d U_{i}^{*} / d \rho_{j}=\lambda_{i}^{*}\left\{R \bar{\theta}_{i j}\left[\left(d p_{j} / d \rho_{j}\right)-\left(d y_{j}^{0} / d \rho_{j}\right)\right]+\right.$ $\left.\theta_{i j} k \sigma_{j}^{2}\right\}$. Thus, all shareholders desire to expand the firm beyond its net value maximizing scale, since net value maximization occurs at the $\rho_{j}$ such that $d p_{j} / d \rho_{j}$ $=d y_{j}^{0} / d \rho_{j}$.

Note that we have used the capital asset pricing model to calculate how shareholders think a change in the risk-return of a firm will affect the price of a firm. From (16) it can be seen that shareholders do not feel that doubling the output of their firm in each state of nature doubles the value of the firm. If output in each state of nature was a separate good then "perfect competition" would mean that doubling output in each state of nature doubles the value of the firm. If in (16)

3. Stiglitz was careful, however, to point out that this assumption of no trade was not a reasonable one to impose except for gaining analytical insights into the problem. 
we had assumed this, then $d p_{j} / d \rho_{j}=p_{j}$ then there would be unanimity in favor of net-value maximization, as can be seen from (15).

Thus, we see that when there is trade, i.e. $\theta_{i j} \neq \bar{\theta}_{i j}$, there need not be unanimity. Leland ([1973], p. 16) and Radner [1974] have shown that if we assume "competitivity" then there will be unanimity. Competitivity means that each consumer believes that if the output of any firm increases by $b \%$ in each and every state of nature, then the value of the firm increases by $b \%$. This assumption leads to implicit prices by which all consumers can unanimously agree about the value of a change in production plan. From (10)-(15); competitivity implies unanimity with respect to net-value maximization.

\section{The Multiperiod Economy}

In the last section we assumed that there was only one trading period in order to survey the literature on unanimity. In this section we return to the model of section 2 where consumers are permitted to trade in period 1 . In equation (8) of section 2 , we see that consumer $i$ 's preference for a change in the $j$ th firm's production decisions $d \rho_{j}$, depends upon three terms. The first term is the period 0 wealth effect, the second term is the period 1 wealth effect, and the third term is the consumption effect (the fourth term is the wealth effect due to the cost of the new inputs). We can use the spanning assumption, (13), along with the first order conditions (5) and (6) to write (8) as

$$
\begin{aligned}
\frac{d U_{i}^{*}}{d \rho_{j}}= & \lambda_{i}^{0}\left[\bar{\theta}_{i j}\left(1-\frac{d y_{j}^{0} / d \rho_{j}}{d p_{j} / d \rho_{j}}\right)-\theta_{i j}\right] \frac{d p_{j}}{d \rho_{j}}+\sum_{t=1}^{T} \lambda_{i t}\left(\theta_{i j}-\theta_{i j}(t)\right) \frac{d p_{j}(t)}{d \rho_{j}} \\
& +\sum_{t=1}^{T} \lambda_{i t} \theta_{i j}(t) \sum_{k=1}^{J} \hat{\alpha}_{j k} p_{k}(t)
\end{aligned}
$$

where we have used the implicit competitivity assumption that $d p_{k} / d \rho_{j}=0=$ $d p_{k}(t) / d \rho_{j}$ for $k \neq j$. Note that $\hat{\alpha}_{j k}$ does not depend upon the signal $t$ because none of the firms' output vectors depends upon $t$. In this model firms must fix their production plans in period 0 , no firm produces any output until period 2 . Consumers may trade in period 1 based upon new information. From (17) it is clear that there will be unanimity if $\bar{\theta}_{i j}=\theta_{i j}=\theta_{i j}(t)$. However even if the Ekern-Wilson-Leland assumption is made that $\bar{\theta}_{i j}=\theta_{i j}$ there will not, in general, be unanimity when $\theta_{i j} \neq \theta_{i j}(t)$.

There is one situation in which there will be unanimity and that is when competitivity is assumed. That is, we can construct the Arrow-Debreu economy for characteristics as of period 1 . If we can write the value of the firm in period 1 at signal $t$ as a melange of characteristics (i.e. an appropriate mixture of securities), for each of which there is a competitive market, then the value of the firm in each signal-state can be computed as in an Arrow-Debreu economy. Grossman-Stiglitz [1976a] show that with the appropriate competitivity assumption, it will always be possible to do the above and there will be unanimity with regard to value 
maximization. Thus, we showed that when the economy is an extension of an Arrow-Debreu economy there will always be unanimity, even if there is trade.

As we argued in section 3, the no trade assumption was crucial to any unanimity theorem which was not a simple extension of an Arrow-Debreu securities market. We argued in this section that new information would give rise to trade; here we argue that the life cycle of the individual will give rise to trade. (Our earlier discussion concerning the stages of the firm provided a third reason for trade to occur continuously in a stock market: firms also have a life cycle.) When individuals are young, they buy shares as a form of saving; when they are old they sell them, presumably to the next generation.

Assume individuals live for two periods. They work the first period, buy shares; in the second period they receive dividends-based on the firm's action in the previous period-make decisions which will determine the dividend the period after, sell their shares, and finally come the proceeds. In that context, it is clear that at the time of the decision, for the decision makers $\theta_{i j}=0$. Hence all firms will maximize their stock market value. Note, however, that if we modify the model to make it a three period model, then there will exist shareholders in the first and third years of their lives. For the former $\theta_{i j}>0$ while for the latter, as before $\theta_{i j}=0$. Hence we cannot be assured that there will be unanimity unless the spanning and competivity assumptions are satisfied. Spanning alone is enough only if there is no trade.

\section{Spanning and the Choice of a Debt-Equity Ratio}

We now return to the one trading period model of section 3 . We suppose that the production plan $y_{j}=\left(y_{j}^{0}, y_{j}^{2}\right)$ has been chosen, and the firm must now decide how to finance $y_{j}^{0}$. Let $D_{j}$ be the period 0 value of the debt issued by firm $j$. Let $1-a$ be the fraction of the firm that the initial shareholders sell to raise capital (i.e. new equity). Then $y_{j}^{0}=D_{j}+(1-a) p_{j}$. Let $B_{j}$ be the principal plus the interest which the firm promises that bondholders will receive in period 2 . Let $b_{i j}$ be the fraction of firm $j$ 's debt held by consumer $i$. Then (1) is replaced by $x_{i}^{2}(s)=\sum_{j} \theta_{i j} \max \left(0, y_{j}^{2}(s)-\right.$ $\left.B_{j}\right)+\sum_{j} b_{i j} \min \left(B_{j}, y_{j}^{2}(s)\right)$. Thus, the consumer's period 2 consumption comes from non-defaulted debt payments and claims to residual output. Similarly (3) is replaced by $x_{i}^{0}+\sum_{j} p_{j} \theta_{i j}+\sum_{j} D_{j} b_{i j} \leqslant \sum_{j} \bar{\theta}_{i j}\left(p_{j}-y_{j}^{0}+D_{j}\right)+\bar{x}_{i}^{0}$. Thus each initial shareholder owns $a \bar{\theta}_{i j}$ percent of the firm which is worth $a \bar{\theta}_{i j} p_{j}=\bar{\theta}_{i j}\left(p_{j}-y_{j}^{0}+D_{j}\right)$.

We assume no trade in period 1 , so the consumer maximizes $U_{i}\left(\bar{x}_{i}^{0}, x_{i}^{1}, x_{i}^{2}\right)$ subject to the above constraints, with respect to $x_{i}^{0}, \theta_{i j}$ and $b_{i j}$. Denote the maximized utility by $U_{i}^{*}\left(B_{j}\right)$. Let $B\left(B_{j}\right)=\left\{s \mid y_{j}^{2}(s)<B_{j}\right\}$ and $N B\left(B_{j}\right)=\left\{s \mid y_{j}^{2}(s)>B_{j}\right\}$. We are interested in a change in the debt-equity ratio keeping the production plan $y$ constant. We can calculate $d U_{i}^{*}\left(B_{j}\right) / d B_{j}$ at $B_{j}$ such that $y_{j}^{2}(s) \neq B_{j}$ for all $s$. This is given by

$$
\frac{d U_{i}^{*}\left(B_{j}\right)}{d B_{j}}=\lambda_{i}^{0}\left(\bar{\theta}_{i j}-\theta_{i j}\right) \frac{d V_{j}}{d B_{j}}+\left(\theta_{i j}-b_{i j}\right)\left[\frac{d D_{j}}{d B_{j}}-\sum_{s \in N B} \nabla_{s} U_{i}\right]
$$

where $V_{j} \equiv D_{j}+p_{j}$, and $\nabla_{s} U_{i} \equiv \sum_{t=1}^{T} \partial U_{i}\left(x_{i}\right) / \partial x_{i}^{2}(t, s)$.

The Modigliani-Miller theorem gives conditions under which a change in the 
debt-equity ratio leaves the value of the firm unchanged. However, the appropriate theorem should be that all shareholders are indifferent about the debt-equity ratio. As can be seen from (18) $d V_{j} / d B_{j}=0$ is not equivalent to $d U_{i}^{*} / d B_{j}=0$. There is one important and well known situation where the two are equivalent, that is when $\theta_{i j}=b_{i j}$. This occurs if there is portfolio separation such that all consumers desire to hold the same mutual fund of all risky assets (e.g. when all consumers homogeneously believe that returns on all securities are multivariate normal), i.e. hold all risky assets in the same proportion.

We feel that the point of the Modigliani-Miller theorem is that the debt-equity ratio is indeterminate because all shareholders are unanimously indifferent between choices of $B_{j}$. For this to be true, it is necessary that $d U_{i}^{*} / d B_{j}=0$, where it is well defined. As can be seen from (18), this will not be true in general. One situation in which it is true is when there is no trade, i.e. $\bar{\theta}_{i j}=\theta_{i j}$, and strong portfolio separation, i.e. $\theta_{i j}=b_{i j}$. But this will not generalize to a multiperiod model just as ex post unanimity does not generalize.

It might be thought that a spanning argument will lead to unanimity in the above context. It does lead to unanimity but it also implies, under weak regularity conditions, that there exist complete markets. See Grossman-Stiglitz [1976a] for a proof of this fact.

\section{On the Value of Value Maximization}

We have attempted to show that most of the unanimity theorems in the literature on spanning make the assumption that there is no trade during the time between the realization of firms' output and the putting of inputs in place. That is, simple spanning theorems concern firms that are not traded on the large stock exchanges of most countries. Stocks traded on these exchanges have a large trading volume every day because consumers get new information about the probability distribution of firm output (i.e. dividends). We have shown that in such an economy consumers will in general disagree about the production plan which their firm should use. This disagreement arises because different stockholders anticipate different capital gains and losses as new information reaches the market concerning firm output.

A unanimity theorem could be proved in a multiperiod context if the assumption of competitivity is made in addition to the assumption of spanning. Though this may seem like a minor additional assumption, it leads to a very strong implication which spanning above does not imply. That is, if there is spanning and competitivity, then stockholders unanimously desire the firm to maximize net market value.

It is the implication of value maximization that leads us to think that the theory is seriously incomplete. There is one class of firms where it is quite easily seen that net-value is not maximized. A closed end mutual fund is a firm which purchases shares of other firms on the stock market. Its only productive decision on a given day is to purchase or sell shares of one firm for cash or shares of other firms. The closed end mutual fund is itself a corporation with shares traded on the stock market. It is a fact that almost all closed end mutual funds sell at a substantial discount (see Sharpe-Sossin [1975]). That is the market value of the mutual funds portfolio is substantially higher than the market value of the mutual fund own 
shares. This means that there is a productive decision available to the manager of the firm which would increase its value. The manager can sell off the portfolio of stocks for cash and then distribute the cash to the mutual fund shareholders. As this is not done we conclude that the shareholders of the mutual fund do not desire the fund to maximize market value.

Most discussions of unanimity involve the choice of production decisions. We argued that the Modigliani-Miller theorem is the result that with no bankruptcy all shareholders are unanimously indifferent among choice of the debt-equity ratio. We showed that if there is a chance of bankrupty, then shareholders need not be unanimously indifferent as to the debt-equity ratio. Since the bonds of the same maturity for different firms have different yields, there must be some chance that firms go bankrupt in the real world. It might be thought that the Modigliani-Miller theorem would still hold if there is spanning for bonds. However, spanning for bonds implies that there are a complete set of markets. This, of course, implies that the debt-equity ratio is indeterminate but it has the empirically false implication that firms maximize value and all risks are insurable.

\section{Equilibrium in THE CoRporate ECONOMY}

What happens when there is no unanimity, as our analysis suggests will generally be the case? And, what happens if there is unanimity but not on the value maximizing strategy, as could be the case when the spanning assumption was satisfied, but not the competitivity assumption? Wouldn't some individual take over the firm, change its policy to the market value maximizing policy, and make a pure capital gain? An answer to these questions and the formulation of a complete equilibrium theory of the market require the specification of assumptions concerning the information available to the shareholder concerning the take-over and the expectations of individuals about the actions to be taken by the firm after the take-over. We argue that there are serious problems in formulating an equilibrium theory of take-overs. (See Grossman-Hart [1976] for a theory of the firm without spanning.)

Assume there is ex ante unanimity on a policy other than value maximization; assume that the individual taking over the firm announces the firm will pursue a value maximizing strategy; individuals know that after the take-over, the individual is going to sell his shares to obtain his capital gain, and that in the new shareholders' meeting following that, all will vote for the original utility maximizing strategy. Thus, in spite of the announcement, individuals do not expect that the firm will pursue a value maximizing strategy, and hence the entrepreneur will not be able to reap any capital gain. In the above example, if the take-over entrepreneur could (because of fixed investments, say) commit the firm to the value maximizing strategy for one period, then, he could obtain a majority of shares at the current market price. But unless the competitivity assumption is satisfied, there is likely to be a downward sloping demand curve for shares of firms. The market value represents the value to the marginal purchaser; to purchase a majority of shares, even acting as a discriminating monopsonist, would be more costly than the current value of the firm.

There are several other problems with arranging a successful take-over even if all 
shareholders desire value maximization, but the current management is against it. (a) If the individual taking over announces it prior to his take-over, then it does not pay anybody to sell his shares; if he expects the take-over to be successful, by postponing selling, the individual would make a capital gain. An exception is where the group taking over offers all shareholders exactly the maximized market value, but in this case there are no profits to be made from the take-over. (b) Another quandry arises if the take-over is not announced but proceeds gradually, then only when the individual owns, say $10 \%$ of the shares, is the take-over bid implicitly disclosed (as current law requires). If a successful take-over bid is associated with an increase in market value, then the market realizing this will immediately bid up the shares upon disclosure. But then, it would pay any entrepreneur to buy $10 \%$ of the shares, simply to obtain a capital gain. But then, of course, disclosure will not be a signal of a take-over bid. Take-overs have many of the informational characteristics of arbitrage discussed in Grossman-Stiglitz [1976a].

We are now prepared to suggest a definition of equilibrium: consider all the policies with the characteristic that a majority of the shareholders who purchase the shares ${ }^{4}$ when that policy is announced, vote for the given policy against any other policy. For each such policy, there is a market value. An equilibrium requires that it be preferred by a majority and be immune from take-over. The policy with the highest market value is the equilibrium. Clearly no other policy can be an equilibrium; for ignoring the quandaries concerning the purchase of the shares, a take-over bid which announced the given policy would be able to sustain the given policy and hence a capital gain could be made. If individuals assume that only policies to be eventually pursued by the firm-and hence the policies which are relevant-are those which can be sustained in the above sense, the market price associated with any other policy must be lower than that market price, and hence there will be no take-over attempts against it.

\section{Concluding Remarks}

This paper has argued that (a) spanning does not imply shareholder unanimity for corporations that are traded. (b) If there is unanimity for a traded firm due to the assumption of competitivity, then firms must maximize value. (c) But closed end funds do not maximize value, and these companies are the ones we would most expect to do so. We thus find spanning an unsatisfactory assumption. (d) We further argue that there are fundamental difficulties with justifying value maximization on the basis of take-over bids when firms are undervalued.

\section{REFERENCES}

P. A. Diamond. [1967], "The Role of a Stock Market in a General Equilibrium Model with Technological Uncertainty," American Economic Review, 57, 759-776.

S. Ekern and R. Wilson. [1974], "On the Theory of the Firm in an Economy with Incomplete Markets," The Bell Journal of Economics and Management Science, Vol. 5, No. 1, 171-180.

4. Clearly, as in any voting model, there may not exist an equilibrium in the stockmarket voting model; it seems there are large costs associated with changing plans and with indecisiveness, and accordingly we suggest the following modification: a majority voting equilibrium is a proposal which cannot be defeated by any proposal which cannot be defeated by some other proposal. 
S. Grossman and J. Stiglitz. [1976a], "On Stockholder Unanimity in Making Production and Financial Decisions," Technical Report No. 250, Economics Series, Institute for Mathematical Studies in the Social Sciences (IMSSS), Stanford University.

and - [1976b], "Information and Competitive Price Systems," American Economic Review, Vol. 66, No. 2, pp. 246-253.

and O. Hart [1976], "A Theory of Competitive Equilibrium in Stock Market Economies," Technical Report No. 230, Económics Series, IMSSS, Stanford University.

H. Leland. [1973], "Capital Asset Markets, Production and Optimality: A Synthesis,” Technical Report No. 115, Economics Series, IMSSS, Stanford University.

[1974], "Production Theory and the Stock Market," The Bell Journal of Economics and Management Science, Vol. 5, No. 1, 125-144.

R. Radner. [1974], "A Note on Unanimity of Stockholders' Preferences Among Alternative Production Plans: A Reformulation of the Ekern-Wilson Model," The Bell Journal of Economics and Management Science, Vol. 5, No. 1, 181-186.

W. F. Sharpe and H. B. Sossin. [1975], "Closed-End Investment Companies in the United States: Risk and Return," in European Finance Association, 1974 Proceedings (B. Jacquillant, editor), North Holland, 37-63.

J. E. Stiglitz. [1970], "On the Optimality of the Stock Market Allocation of Investment," paper presented at the Far Eastern Meetings of the Econometric Society, Tokyo, June 27-29, 1970.

. [1972], "Some Aspects of the Pure Theory of Corporate Finance: Bankruptcies and TakeOvers," The Bell Journal of Economics and Management Science, Vol. 3, No. 2, Autumn 1972, 458-482. 
Copyright of Journal of Finance is the property of Blackwell Publishing Limited and its content may not be copied or emailed to multiple sites or posted to a listserv without the copyright holder's express written permission. However, users may print, download, or email articles for individual use. 